\title{
O INCONSCIENTE E A CONSCIÊNCIA: DA PSICANÁLISE À NEUROCIÊNCIA'
}

\section{Carlos Eduardo de Sousa Lyra ${ }^{2}$}

Resumo: Este artigo consiste numa revisão acerca dos conceitos de "inconsciente" e "consciência", a partir dos pontos de vista da psicanálise e da neurociência. $O$ autor examina, inicialmente, o Projeto freudiano. Em seguida, aborda as críticas de Searle à psicanálise, e apresenta a proposta de Damásio e as concepções de Edelman acerca da consciência. Por fim, indica algumas possíveis contribuições das teorias neurocientíficas para a prática e a teoria psicanalíticas.

\section{Palavras-chave: Psicanálise. Neurociências. Psicopatologia. Psicoterapia.}

Conbecemos duas espécie de coisas sobre o que chamamos nossa psique (ou vida mental): em primeiro lugar, seu órgão corporal e cena de ação, o cérebro (ou sistema nervoso), e, por outro lado, nossos atos de consciência, que são dados imediatos e não podem ser mais explicados por nenhum outro tipo de descrição. Tudo o que jaz entre eles é-nos desconhecido, e os dados não incluem nenhuma relação direta entre esses dois pontos terminais de nosso conbecimento. Se existisse, no máximo permitir-nosia uma localização exata dos processos da consciência e não nos forneceria auxilio no sentido de compreendê-los.

(Freud, 1940/1990)

1 Parte do artigo foi extraída de dissertação de mestrado produzida sob orientação da Profa. Dra . Ana Rudge, na Pontifícia Universidade Católica do Rio de Janeiro, com o auxílio da CAPES.

2 Psicólogo, bacharel em Filosofia e mestre em Psicologia Clínica. E-mail: ceslyra@hotmail.com 


\section{Introdução}

O problema da consciência é bastante antigo: foi investigado amplamente pelos filósofos, principalmente os modernos; e tornou-se também, a partir do século XIX, objeto de estudo de psicólogos e fisiologistas.

Entre os psicólogos que se ocuparam do tema, podemos destacar Wilhelm Wundt e o seu estruturalismo, cujo objeto de estudo era a experiência consciente. Wundt analisou as estruturas do psiquismo humano pelo método introspectivo (ou introspecção psicológica), adotando o modelo de investigação científica das ciências naturais, a exemplo da física e da fisiologia. Para o estruturalismo, o componente primordial da consciência é a sensação. Esta se classifica segundo modalidade, intensidade e duração (Rosa, 1995). Ao longo de sua carreira, Wundt realizou inúmeras experiências e elaborou diversas teorias, embora tenha sido bastante criticado pelo seu método de estudo - a introspecção. Não obstante, contribuiu na definição de uma identidade para a psicologia, utilizando métodos baseados na observação, experimentação e mensuração no estudo da experiência consciente.

Durante muito tempo, a psicologia, enquanto ciência empírica, procurou seguir o modelo das ciências naturais, tendendo, na maioria das vezes, a reduzir as diferenças entre sujeito e objeto, e adotando uma concepção naturalista. Para os naturalistas, a consciência não passa de um epifenômeno: emerge dos processos quantitativos e das relações causais que se realizam no cérebro. Husserl criticou severamente o psicologismo, defendendo uma posição dualista, na qual a consciência ocupa um lugar relevante em relação às coisas na natureza. Herdeiro do pensamento cartesiano, Husserl concebe a consciência como um fenômeno qualitativo, dotado de intencionalidade, isto é, que visa a um determinado objeto. Igualmente, para Husserl, o psíquico é um fenômeno, e não a coisa (Husserl, 2000). Dessa forma, o psíquico não pode ser reduzido ao físico - ou, ainda, a mente não pode estar numa relação de identidade com o cérebro. Portanto, para a fenomenologia de Husserl, a consciência encerra o domínio do psíquico.

A concepção fenomenológica da consciência, por sua vez, passou a ser questionada pela psicanálise, uma vez que Freud estende a qualidade de "psíquico" também aos fenômenos inconscientes (Freud, 1923/ 1990).

\section{O 'Projeto' freudiano}

Em 1895, Freud escreve sua "Psicologia para neurologistas" - texto mais conhecido como"Projeto para uma Psicologia Científica”,e que seria publicado postumamente, em 1950. Nessa obra, declara sua intenção de 
construir uma teoria psicológica fundamentada nas ciências naturais (Freud, 1950/1990).Toda a sua argumentação toma como ponto de partida dois conceitos: 1) o de uma quantidade (Q) em movimento; e 2) o de neurônios como partículas materiais. Não obstante, no Projeto, Freud utiliza um vocabulário neurológico para falar de noções psicológicas. Embora partisse de suas observações clínicas acerca das psicopatologias de sua época para formular suas teorias, não podemos descartar o fato de que Freud era neurologista e, tendo sido por alguns anos pesquisador nessa área, conhecia muito bem o funcionamento do sistema nervoso, de tal maneira que esses conhecimentos devem ter contribuído para um entendimento mais apurado das relações entre os conceitos que formulou.

No Projeto, Freud postula a existência de dois tipos de neurônios: 1) os neurônios phi (permeáveis), que permitem a passagem de $Q$ sem que haja uma alteração no nível de excitação; e 2) os neurônios psi (impermeáveis), que permitem apenas uma passagem parcial de $Q$, em virtude da presença ativa das barreiras de contato. Assim, apenas os neurônios psi apresentam resistência à descarga e, portanto, podem representar uma memória (Freud, 1950/1990). Os neurônios phi, por sua vez, são responsáveis pela percepção sensível (o que envolve apenas a percepção de uma quantidade [sensação] e não de uma qualidade [percepção-consciência]). Segundo o autor, a função da memória está relacionada à existência de facilitações entre os neurônios psi, que tendem a torná-los menos impermeáveis, ou seja, semelhantes aos neurônios phi.

Freud afirma que os neurônios psi, além de se comunicarem com os neurônios phi, recebem catexias (investimentos) a partir do interior do corpo ("estímulos endógenos"); e que "é provável que os neurônios psi devam ser divididos em dois grupos: os neurônios de pallium, que são catequizados a partir de phi, e os neurônios nucleares, catexizados a partir das vias endógenas de condução" (Freud, 1950/1990, p. 428). Os estímulos endógenos, segundo Freud, têm origem intercelular e são produzidos de forma contínua pelo organismo, transformando-se em estímulos psíquicos apenas periodicamente. As Qs endógenas atuam apenas por soma de excitação, pois se constituem originalmente de parcelas mínimas de excitação - é, portanto, a soma dessas parcelas mínimas que, eventualmente, chegará aos neurônios psi-nucleares. É somente quando as Qs endógenas chegam aos neurônios psi-nucleares que podemos caracterizá-las como "pulsões". 
Em uma determinada passagem do Projeto, Freud passa a se referir ao "problema da qualidade" e ao "da consciência", os quais considera fundamentais na elaboração de uma teoria psicológica, "independentemente do que se realiza do ponto de vista da ciência natural" (Freud, 1950/1990, p. 418). Estabelece que os processos neuronais "devem ser considerados em sua totalidade, antes de mais nada, como inconscientes, e devem ser inferidos como os demais fenômenos naturais" (Freud, 1950/1990, p.419). Contudo, é necessário que haja uma percepção qualitativa e consciente dos fenômenos e objetos da realidade externa. Essa percepção-consciência deveria emergir, segundo Freud, do sistema de neurônios psi.

Para resolver o problema acima, Freud postula a existência de um terceiro sistema de neurônios (futuro "sistema Pcpt.-Cs."), os neurônios ômega (perceptivos), que são excitados durante uma percepção, mas não durante uma reprodução (ou recordação), uma vez que não são dotados de memória. Esses neurônios seriam, então, os responsáveis pela percepção consciente das qualidades, e estariam catexizados (investidos) com uma $\mathrm{Q}$ mínima (inferior àquela que circula no sistema psi, porém provinda deste) (Freud, 1950/1990). Ao vindicar a existência dos neurônios ômega, Freud introduz a noção de temporalidade ou período. Assim, presume "que toda a resistência das barreiras de contacto se aplica somente à transferência de $\mathrm{Q}$, mas que o período do movimento neuronal é transmitido a todas as direções sem inibição, como se fosse um processo de indução" (Freud, 1950/1990, p. 421). Em última instância, os neurônios ômega não receberiam $\mathrm{Q}$, mas apenas um período de excitação. Freud acrescenta duas características ao sistema de neurônios ômega: 1) a capacidade de gerar motilidade (isto é, transformar $\mathrm{Q}$ em movimento físico) - quando isso ocorre, há uma descarga e uma perda simultânea da qualidade e do período associado a esta; e 2) a capacidade de agregar sensações de prazer ou desprazer às qualidades.

A questão da "qualidade" é um problema antigo nas ciências naturais, que nos remete a Aristóteles, o qual defendia ser "impossível fornecer uma dedução matemática da qualidade" (Koyré, 1982, p. 169). Assim, toda ciência moderna, a partir de Descartes, deixa de lado o problema da qualidade, por considerá-lo de ordem subjetiva. Não obstante, Freud procura incluir a "qualidade" em seu sistema explicativo, uma vez que uma teoria psicológica completa não pode prescindir dessa categoria epistemológica. Dessa maneira, Freud se depara com os limites entre, por um lado, uma teoria baseada apenas em pressupostos das ciências naturais e, por outro, uma teoria dinâmica acerca da consciência. Isso fica claro na seguinte passagem: 
Segundo uma avançada teoria mecanicista, a consciência é um mero apêndice aos processos fisiológico-psíquicos e sua omissão não acarretaria alteração na passagem psíquica [dos acontecimentos]. De acordo com outra teoria, a consciência é o lado subjetivo de todos os eventos psíquicos, e é assim inseparável do processo mental fisiológico. A teoria aqui elaborada situa-se entre essas duas. (Freud, 1950/1990, p. 423)

Ainda no Projeto, Freud define o ego como um conjunto específico de neurônios psi catexizados (investidos) e bem facilitados entre si; no entanto, o ego não é capaz de distinguir uma idéia (lembrança) de uma percepção sem que haja uma indicação da realidade. Essa indicação qualitativa (que, posteriormente, será chamada de "teste da realidade") é, segundo Freud, fornecida provavelmente pelos neurônios ômega.Trata-se, para o autor, de encontrar um critério para estabelecer uma diferença entre a percepção alucinatória, proveniente da catexia de desejo no sistema psi, e a percepção qualitativa da realidade externa, que é uma função dos neurônios ômega. A percepção qualitativa da realidade só pode ser realizada de forma adequada pelos neurônios ômega se houver uma inibição, por parte do ego (catexizado), das intensas catexias de desejo provenientes do sistema psi. Caso contrário, o ego falha em sua função, e ocorrem as alucinações. É importante mencionar que, para Freud, uma catexia perceptiva é sempre uma catexia de complexos de neurônios, e nunca de neurônios isolados (Freud, 1950/1990). Tendo em vista a diferença entre percepção alucinatória e percepção qualitativa da realidade, Freud atribui ao pensamento a qualidade de ser um processo psíquico secundário; enquanto nos sonhos, por exemplo, predominam os processos psíquicos primários. Do ponto de vista econômico, portanto, o papel do ego seria o de realizar a inibição dos processos psíquicos primários.

Freud volta a se referir ao problema da consciência em outros momentos de sua obra; não obstante, trata-se de passagens corriqueiras, que não esclarecem muito acerca da questão. Assim, em A Interpretação de Sonhos, Freud define a consciência (Cs.) como "um órgão sensorial para a percepção de qualidades psíquicas" (Freud, 1900/2001, p. 587). Aproxima, portanto, a consciência ao sistema Pcpt., de tal maneira que podemos chamar esse sistema de Pcpt.-Cs., recuperando, dessa forma, o sentido estabelecido no Projeto para denominar o sistema ômega (perceptivo). Em 1915, Freud afirma que o controle e a percepção da afetividade (assim como a motricidade) devem ser atribuídos à consciência (Cs.) (Freud, 1915/2006). Por último, em "Além do Princípio de Prazer", Freud (1920/1990) volta a abordar a questão da consciência; contudo, não parece acrescentar nada de novo ao que já havia elaborado antes, principalmente no Projeto. Uma provável e esclarecedora contribuição à questão teria sido o artigo metapsicológico sobre a consciência, que 
deveria ser publicado na série de artigos de 1915 mas extraviou-se. Seu conteúdo jamais foi conhecido.

\section{As críticas de Searle}

John R. Searle, filósofo da linguagem e da mente, pretende apresentar uma visão crítica e inovadora acerca do problema mente-corpo, que seja uma alternativa tanto às concepções materialistas quanto às dualistas (Searle, 1997). Nesse sentido, Searle recorre a argumentos biológicos para defender a tese de que a mente/cérebro possui uma intencionalidade intrínseca, a qual também se expressa em termos lingüísticos. Além da intencionalidade, Searle propõe uma teoria da mente que leve em consideração a questão da consciência. Esta, por sua vez, também seria intrínseca à mente/cérebro.

De acordo com Searle, "os fenômenos mentais são causados por processos neurofisiológicos no cérebro, e são, eles próprios, características do cérebro" (Searle, 1997, p. 7). O autor defende, portanto, uma concepção que denomina "naturalismo biológico". Sua proposta pretende abarcar questões que se situam tanto no campo das neurociências quanto nos da psicologia e da filosofia.

Para Searle, a consciência é tão física quanto mental, uma vez que a característica de "ser mental" implica necessariamente "ser físico". Ainda de acordo com o filósofo, qualquer investigação sobre a mente deve apontar necessariamente para o estudo da consciência. Dentre as principais características da consciência, uma parece ser fundamental para o seu estudo: a perspectiva em primeira pessoa. Em outras palavras, podese afirmar que a consciência é sempre subjetiva, relativa a um "eu". Dessa forma, Searle critica severamente o uso da perspectiva em terceira pessoa nas pesquisas sobre a consciência; nesse sentido, não se trata de abandonar o estudo objetivo do comportamento, mas de reconhecer que o comportamento por si só não é suficiente para descrever a consciência, dado o caráter subjetivo desta.

Dentre outras características da consciência relacionadas por Searle (1997), podemos destacar: 1) a presença de modalidades finitas (os sentidos da visão, audição, tato, olfato, paladar, equilíbrio e propriocepção; além do fluxo de pensamento);2) a unidade (que envolve uma experiência total, i. e., a soma das imagens parciais em uma mesma unidade num mesmo período de tempo); 3) a intencionalidade (i. e., a qualidade de "ser acerca de alguma coisa"); 4) o seu aspecto gestáltico (i. e., sua capacidade de focalizar a atenção entre figura e fundo);5) a familiaridade (que permite reconhecer uma determinada cena ou objeto como pertencente à vivência subjetiva de determinada pessoa); 6) a dimensão prazer/ desprazer. 
Como podemos perceber, boa parte das características reunidas por Searle para definir a consciência foram levadas em conta por Freud nos momentos em que este tentou inserir a questão da "qualidade" e da "percepção-consciência" em seu estudo dos processos inconscientes. Não obstante, Searle critica o conceito de inconsciente utilizado por Freud. De uma forma geral, Searle procura mostrar que o estudo dos processos inconscientes tornou quase impossível o estudo da consciência, uma vez que esta foi relegada a um produto final de todos os processos que ocorrem no psiquismo. Segundo Searle (1997), ainda, essa tendência já estava presente na psicanálise e influenciou toda tradição psicológica posterior. As críticas de Searle, por sua vez, têm o objetivo de fundamentar sua proposta de trazer o estudo da consciência novamente para o primeiro plano.

Mais especificamente, Searle vai basear suas críticas ao conceito de "inconsciente" na noção de que tudo o que se encontra em estado inconsciente é acessível pela consciência, ou seja, o inconsciente é potencialmente consciente ("princípio de conexão"). Inicialmente, Searle vai considerar, para seus argumentos, o conceito de "inconsciente" como "a idéia de um estado mental consciente menos a consciência" (p. 218). Searle parece, portanto, defender a suposição de que todo estado mental deve ser consciente, isto é, que o fato de ser "mental" implica em "ser consciente". Não obstante, reconhece que a definição descritiva do termo "inconsciente" - i.e.,"a idéia de um estado mental que apenas acontece de ser inconsciente neste momento" (p. 219) - é a que prevalece no entendimento comum do termo. Nesse último sentido, aceita a noção freudiana de "pré-consciente" como sendo compatível com a idéia de que, descritivamente falando, há estados mentais inconscientes que são idênticos a estados conscientes. Assim, o principal problema recairia sobre o inconsciente reprimido (recalcado), uma vez que o seu acesso à consciência só poderia se dar através de substitutos (ou derivados) préconscientes/conscientes (Freud, 1915/2006).

De acordo com Searle, uma teoria sobre o inconsciente deve ser capaz de explicar a diferença entre intencionalidade intrínseca e intencionalidade como-se, isto é, "justificar a distinção entre os fenômenos que são genuinamente intencionais e aqueles que, em alguns aspectos, se comportam como se fossem, mas na realidade não são"(Searle, 1997, pp. 222-223). Assim, para Searle, somente a intencionalidade intrínseca poderia ser considerada como "mental."A descrição de um evento que não possui uma intencionalidade intrínseca, mas do qual se pode supor uma intencionalidade a partir da forma como o evento descrito se assemelha a um evento intrinsecamente intencional, por sua vez, não pode ser considerada como descrição de um evento "mental."Os estados intencionais inconscientes (o que incluiria o inconsciente reprimido) são intrínsecos, ou seja, não podem ser considerados como metáforas ou como se fossem intencionais. 
Uma teoria sobre o inconsciente também deve considerar, segundo Searle, que a intencionalidade é satisfeita apenas a partir de certos aspectos ("forma aspectual") acerca dos objetos que são percebidos por um sujeito ("agente"). Isto estaria relacionado com a percepção-consciência: um objeto é sempre percebido como consciente sob um determinado ponto de vista e a partir de determinadas características que podem ser atribuídas ao mesmo. Nesse sentido, a"forma aspectual" da consciência só poderia ser completamente descrita a partir do ponto de vista em primeira pessoa.

Searle (1997) defende que os estados mentais inconscientes, no momento em que estão latentes, são ontologicamente idênticos aos fenômenos neurofisiológicos. Não obstante, dizer que os estados mentais inconscientes correspondem aos eventos neurofisiológicos que ocorrem no cérebro é contraditório com a descrição dos estados mentais do ponto de vista em primeira pessoa. Mas Searle insiste que tais estados intencionais inconscientes são potencialmente conscientes, ou seja, constituem pensamentos ou experiências passíveis de se tornarem conscientes, ou que já foram conscientes outrora. Assim, ontologicamente, o inconsciente "consiste em características objetivas do cérebro capazes de causar pensamentos conscientes subjetivos" (p. 230). Dessa forma, um estado mental inconsciente está sempre implicado numa relação de causalidade com outros estados mentais latentes, podendo eventualmente produzir estados mentais conscientes. O bloqueio dessa causalidade, segundo Searle, poderia ocorrer eventualmente, devido à repressão (recalque) ou a alguma lesão cerebral.

Searle termina por concluir o seguinte:"Não há nada acontecendo em meu cérebro a não ser processos neurofisiológicos, alguns conscientes, alguns inconscientes. Dentre os processos inconscientes, alguns são mentais, outros não". Assim, apenas os estados inconscientes capazes de causar estados conscientes podem ser relacionados como"mentais".Searle chama esses estados mentais inconscientes de "superficialmente inconscientes" em contraposição aos estados inconscientes não-mentais, que seriam "profundamente inconscientes" (p. 232), e conclui que estes últimos simplesmente não existem.

De acordo com o filósofo, algumas descrições freudianas acerca de desejos, crenças e intenções (que parecem caracterizar o que Freud denomina de "inconsciente reprimido") se aplicam ao que ele classifica como "superficialmente inconsciente", embora os considere mais bem definidos como sendo "casos de consciência reprimida, porque estão sempre borbulhando para a superfície, embora freqüentemente numa forma disfarçada" (p. 247). Já outras crenças, desejos e intenções que estão ausentes da consciência apenas num dado momento, mas que são potencialmente conscientes, também poderiam ser definidos como "superficialmente inconsciente", mas se aplicariam apenas ao que Freud deno- 
mina de "pré-consciente". Os fenômenos mentais classificados por Searle como "profundamente inconscientes" (isto é, ao mesmo tempo inconscientes e inacessíveis à consciência), por sua vez, não poderiam existir, de acordo com uma lógica que pressupõe a intencionalidade.

Tendo em vista a noção de "estados mentais inconscientes" fornecida por Searle, bem como seus argumentos críticos em relação ao inconsciente freudiano, podemos concluir o seguinte: o critério utilizado por Searle para definir os estados mentais inconscientes é o tempo todo marcado por uma concepção lógica de intencionalidade, isto é, está fundamentado nas leis da linguagem. Se deixarmos de lado o ponto de vista descritivo do termo "inconsciente" e considerarmos o ponto de vista dinâmico, poderemos então falar de estados mentais conscientes, préconscientes e inconscientes. Assim, esses estados mentais dinâmicos possuiriam uma causalidade, bem como uma intencionalidade, e estariam estruturados como uma linguagem. Podemos, portanto, incluir o inconsciente reprimido entre os estados mentais dinâmicos acima relacionados. Todo processamento neurofisiológico relacionado a esses estados mentais, por sua vez, se daria no nível das memórias explícitas (potencialmente conscientes). Dessa forma, a proposta de Searle não seria incompatível com os conceitos dinâmicos de consciente, pré-consciente e inconsciente, uma vez que todos esses processos são psíquicos (ou seja, mentais) e estariam incluídos na definição de "superficialmente inconsciente"; além disso, envolveriam representações de palavra, isto é, memórias explícitas.

Já o que Searle classifica como "profundamente inconsciente" incluiria basicamente o núcleo do sistema inconsciente (Ics.) freudiano, ou seja, aqueles representantes pulsionais que jamais se tornam conscientes, a não ser por meio dos seus derivados pré-conscientes/conscientes (Freud, 1915/2006). Nesse sentido, estaríamos lidando com um inconsciente anterior ao recalque originário (ou maturação do hipocampo), isto é, anterior à linguagem (Lyra, 2005). Trata-se de um inconsciente implícito, que envolveria as representações de coisa, isto é, memórias implícitas. A crítica de Searle, portanto, só se aplicaria ao inconsciente explícito, uma vez que o critério utilizado pelo filósofo é, sobretudo, um critério lingüístico. Nesse sentido, Searle ignora o funcionamento do inconsciente implícito. Contudo, poderíamos manter aberta a discussão sobre se seria possível uma intencionalidade e uma causalidade não-lingüísticas que se aplicariam ao que chamamos de "inconsciente implícito". A existência de uma causalidade implícita certamente seria algo mais fácil de se comprovar. Porém, afirmar a existência de uma intencionalidade implícita, que não envolveria uma relação lingüística com os objetos, é um desafio que deve ser seriamente levado em conta se quisermos defender uma concepção mais ampla do conceito de inconsciente. 


\section{A proposta de Damásio}

Um autor que abordará a questão da consciência sem necessariamente cair no paradigma lingüístico é Antônio Damásio. Com sua abordagem, podemos investigar a noção de uma causalidade e de uma intencionalidade que estariam presentes na consciência, mesmo na ausência de uma linguagem. Se pudermos admitir, portanto, a existência de uma consciência não-lingüística dotada de causalidade e intencionalidade, poderemos então admitir também a possibilidade de um inconsciente implícito que estaria diretamente relacionado a essa consciência.

Neste sentido, Damásio (2000) apresenta argumentos e dados clínicos que sugerem a existência de uma consciência central, dotada de causalidade e intencionalidade, pois envolve "uma interação entre um organismo e um objeto" (p. 219), ambos representados no cérebro do organismo em mapas neurais de primeira ordem, cujos padrões podem se tornar imagens. Afirma o autor:"Os mapas sensório-motores pertinentes ao objeto causam mudanças nos mapas pertinentes ao organismo" (p. 219). Não apenas o próprio organismo e o objeto são representados como mapas de primeira ordem, como também a interação entre ambos é representada no cérebro como mapas de segunda ordem, os quais, por sua vez, também geram imagens mentais (relatos não-verbais). Essas imagens mentais geradas pela relação entre organismo e objeto seriam os sentimentos.

De acordo com Damásio, essa relação entre organismo e objeto, capaz de causar imagens mentais, é vivenciada no nível de uma consciência central e se caracteriza pela presença de um self central. Assim,

as imagens do objeto afetam o estado do organismo.... O mapeamento das conseqüências relacionadas ao objeto ocorre em mapas neurais de primeira ordem que representam o proto-self e o objeto; o relato da relação causal entre objeto e organismo somente pode ser captado em mapas neurais de segunda ordem. (p. 220)

A produção de um relato não-verbal de segunda ordem, portanto, cria uma narrativa. Nesse sentido, Damásio está lidando abertamente com uma intencionalidade como-se (Searle, 1997), na medida em que atribui uma narrativa metafórica a relatos não-verbais. Por sua vez, a sucessão de narrativas, isto é, a interpolação de imagens mentais, é capaz de modificar o proto-self e de produzir um fluxo de pensamento que podemos associar a uma consciência central.Segundo Damásio, essa vivência consciente de um organismo implica a existência de um "self central transitório", uma vez que o relato imagético do objeto dura apenas enquanto a atenção do organismo está voltada para o mesmo objeto. Trata-se, por- 
tanto, de uma memória do presente, de uma percepção consciente em um nível elementar.

Não obstante, Damásio afirma que, em organismos mais complexos, dotados de vasta capacidade de memória e associações entre essas memórias, algo da vivência consciente subjetiva permanece para além de um self central transitório. Esse conjunto de memórias autobiográficas, "que concernem tanto ao passado como ao futuro antevisto" (Damásio, 2000, pp. 223-224), será a base do que Damásio vai chamar de "self autobiográfico". Assim, o self autobiográfico está embasado na existência de memórias autobiográficas, que, por sua vez, são memórias implícitas. A consciência dessas memórias, num nível elementar, produz o self autobiográfico. Portanto, toda autobiografia de um determinado indivíduo pode ser acessada a partir dessas memórias implícitas de experiências individuais, sem que isso implique, a priori, qualquer vinculação com a linguagem. A presença da linguagem na espécie humana seria conseqüência de uma tradução simultânea da memória autobiográfica implícita em memória explícita, o que envolve o papel do hipocampo (LeDoux, 2000).

Tendo em vista a existência de memórias implícitas autobiográficas, podemos não apenas supor a ocorrência de um self autobiográfico, como também afirmar a existência de um inconsciente implícito, que se caracterizaria pelo conjunto de memórias implícitas "profundamente inconscientes", mas potencialmente acessíveis à consciência central.

Posteriormente, Damásio vai se referir a uma consciência ampliada, que está relacionada à idéia comum que temos do conceito de "consciência", isto é, a consciência humana. Essa consciência ampliada tem por base a consciência central; porém, é capaz de realizar atividades bem mais complexas, como acessar e modificar memórias do passado e de um futuro antevisto. A consciência ampliada também é capaz de estender a memória a um período de tempo bem mais longo, em comparação à transitoriedade da consciência central. Nesse sentido, a consciência ampliada está relacionada à existência de uma memória operacional (ou memórias de trabalho), capaz de manter a percepção consciente de vários objetos numa mesma unidade em um período de tempo que vai de segundos até alguns minutos (Damásio, 2000).

É somente quando nos deparamos com a existência de uma consciência ampliada que podemos falar de um inconsciente explícito, uma vez que a consciência ampliada só estaria presente nos seres humanos, que, por sua vez, são dotados de linguagem. Tendo em vista a íntima relação entre consciência ampliada e memória operacional, podemos afirmar que somente uma consciência dotada de uma memória seletiva poderia realizar mecanismos como a supressão e a repressão de memórias (Izquierdo, 2002). Além disso, o papel executivo e seletivo atribuído à memória operacional (ou de trabalho) é semelhante àquele atribuído ao 
"ego" postulado por Freud. Isto reforça a hipótese de que o conjunto sistemático da memória operacional (que poderíamos chamar de "ego"), o qual se localizaria no córtex pré-frontal (Izquierdo, 2002), é o responsável pelo que Freud denomina de supressão [Unterdrückung], bem como pela repressão (ou recalque secundário) [Verdrängung]. O papel do recalque originário [Urverdrängung], por sua vez, seria o de realizar a "tradução" de memórias implícitas em memórias explícitas, o que seria uma função do hipocampo (Lyra, 2005).

\section{As concepções de Edelman}

Gerald M. Edelman (1998) defende que a mente emerge da matéria que constitui o cérebro. Procura inserir a psicologia na discussão biológica a respeito da consciência. Assim como Damásio (2000), Edelman (1998) vai distinguir entre dois tipos de consciência. A primeira diz respeito às imagens mentais que temos do presente, isto é, a uma memória do presente; esta seria, segundo Edelman, a definição para o que ele chama de "consciência primária". Por outro lado, há um modo de conhecimento da realidade que envolve a capacidade de nos referirmos tanto ao passado quanto ao futuro, e que envolve o uso da linguagem; este seria o que Edelman chama de "consciência elaborada". Diferentemente de Damásio, Edelman defende que a presença de um "eu" só ocorre em indivíduos que possuem uma consciência elaborada, marcada pela linguagem e capaz de voltar-se para si mesma.

De acordo com Edelman (1998), uma teoria completa acerca da consciência deve se basear na evolução das espécies, como também deve estabelecer conexões entre a consciência e as demais funções mentais, em especial a memória e a linguagem. Nesse sentido, uma teoria sobre a consciência deve estar fundamentada no conhecimento científico acerca do cérebro e do sistema nervoso. Edelman vai sistematizar essas condições a partir de três pressupostos: 1 ) um pressuposto físico, que advoga que uma teoria sobre a consciência não pode violar os princípios estabelecidos pela física, embora também possa contribuir para ampliar esse conhecimento; 2 ) um pressuposto evolutivo, que defende a noção de que a consciência surgiu como propriedade fenotípica num determinado momento da evolução das espécies, o que implica que a consciência possui um valor adaptativo dentro da cadeia evolutiva; e 3) o pressuposto dos qualia, que afirma que uma teoria acerca da consciência deve considerar a existência de estados fenomenais que se apresentam como "um conjunto de experiências, sentimentos e sensações pessoais ou subjectivas que acompanham o estar consciente" (p. 167).

Segundo o autor, o pressuposto físico garante que espíritos e fantasmas não intervêm sobre a consciência, assim como o pressuposto 
evolutivo implica que a consciência não é um mero epifenômeno, tendo, portanto, uma eficácia causal.Já o pressuposto dos qualia é, para Edelman, uma noção mais complexa, que envolve principalmente a consciência humana, ou seja, a capacidade de integrar os diversos elementos de uma determinada cena numa mesma unidade, além da possibilidade de relatar essa vivência subjetiva em primeira pessoa. É a presença dos qualia que torna possível fazer a distinção entre a consciência elaborada e a consciência primária.

Como podemos perceber, apesar de apresentar pontos em comum, a teoria de Edelman sobre a consciência se diferencia claramente da teoria de Damásio, uma vez que o primeiro reserva um lugar privilegiado para a linguagem em sua teoria explicativa. Essa característica da teoria de Edelman é que faz da mesma uma teoria compatível, em maior escala, com os pressupostos da teoria freudiana acerca da mente humana. A presença da linguagem, como legitimadora de uma consciência elaborada, é claramente compatível com a idéia freudiana da existência de um "recalque originário" e da possibilidade de um inconsciente explícito, estruturado como uma linguagem.

No que diz respeito ao sistema nervoso, Edelman afirma que podemos concebê-lo a partir da existência de dois modos de organização, que compreendem duas etapas da evolução da consciência. O primeiro modo de organização inclui o tronco cerebral e o sistema límbico, que possui ligações com o sistema endócrino e o sistema nervoso autônomo; de acordo com Edelman (1998), esse sistema límbico-troncular é um sistema de valores, e está diretamente relacionado às funções corporais e internas. (Essa descrição de Edelman sugere uma aproximação com o que Freud descreve como sendo o sistema de neurônios - $p$ sinuclear no "Projeto".)

O segundo modo de organização inclui uma ação simultânea do tálamo e do córtex cerebral, o que nos permite nomeá-lo de sistema corticotalâmico. Esse sistema, bem mais recente na cadeia evolutiva, é o responsável pela interação com o mundo externo (através dos órgãos do sentido e da motricidade), bem como pela aprendizagem e categorização dos acontecimentos. (Aqui, pode-se sugerir uma aproximação com as funções desempenhadas pelo que Freud chama, no "Projeto",de sistema de neurônios psi pallium em conjunção com o papel atribuído aos neurônios ômega [perceptivos]). É importante, ainda, mencionar a existência de alguns apêndices do córtex - o cerebelo, os gânglios basais e o hipocampo -, que evoluíram em conjunto com a estrutura cortical.

De acordo com Edelman (1998), os sistemas límbico-troncular e corticotalâmico atuam em conjunto no processo global de aprendizagem, sendo que o primeiro é responsável pela atribuição de um valor evolutivo e adaptativo às experiências do indivíduo; valor este que servi- 
rá de base para o processo de categorização dos acontecimentos relacionados ao mundo externo. A interação entre ambos os sistemas mencionados, portanto, dá origem a um novo tipo de memória, que Edelman chama de memória de "valor-categoria", o qual vai além da mera categorização perceptiva. A presença de um circuito reentrante, que estabelece a comunicação contínua entre a memória de valor-categoria e as imagens reais do mundo, fornecidas pela categorização perceptiva, seria o elemento-chave que teria permitido, segundo Edelman, o surgimento da consciência primária.

Podemos relacionar os processos neurais e os modos de organização descritos por Edelman com o que chamamos de "inconsciente implícito", isto é, um conjunto sistemático de memórias implícitas. Assim, o núcleo desse inconsciente implícito estaria localizado no sistema límbicotroncular (no qual podemos destacar o papel da amígdala), e seria o responsável pela origem das emoções e das memórias emocionais implícitas (LeDoux, 2000), de tal maneira que poderíamos chamá-lo de "inconsciente emocional".Já o sistema corticotalâmico e seus apêndices (especialmente os gânglios basais e o cerebelo) estariam relacionados com o que Kandel (1999) chama de "inconsciente procedural", que consiste em memórias procedurais implícitas. Assim, o inconsciente implícito seria constituído tanto por memórias emocionais quanto por memórias procedurais, ambas memórias implícitas.

A entrada no mundo simbólico só foi possível com o advento da linguagem nos seres humanos, fato que a psicanálise atribui ao recalque originário. Edelman, por sua vez, vai relacionar o advento da fala e da linguagem com o surgimento da consciência elaborada e do"eu."De acordo com Edelman (1998), a capacidade de atribuir significados às coisas já está presente antes da epigênese da fala, isto é, antes do aparecimento da linguagem. Isto implica que o significado é anterior ao significante. Portanto, assim como o "bootstrapping perceptivo" (conexão entre as imagens percebidas pelos sentidos e a memória categoria-valor) estaria na origem da consciência primária, o "bootstrapping semântico" (epigênese da fala e advento da linguagem) estaria na origem da consciência elaborada. Assim, o recalque originário equivaleria ao que Edelman chama de "bootstrapping semântico".

Edelman (1998), então, resume sua concepção evolutiva da consciência apresentando uma cartografia do cérebro que segue a seguinte ordem: seleção de grupos neuronais no tronco cerebral, hipotálamo e sistema nervoso autônomo (responsáveis pelo "valor" adaptativo), em paralelo à seleção de grupos neuronais nas áreas corticais primárias (responsáveis pela percepção); a percepção e o valor, através de uma cartografia reentrante, dão origem à categorização perceptiva; o"bootstrapping perceptivo", por sua vez, dá origem à consciência primária, como também é condição necessária para que possa ocorrer uma categorização 
conceptual (que está relacionada com os córtices frontal, temporal e parietal); por último, o "bootstrapping semântico" dá origem à consciência elaborada.

A aprendizagem, segundo Edelman, começa a ocorrer a partir da categorização perceptiva e vai se tornando um processo cada vez mais complexo, culminando na consciência elaborada. O"bootstrapping semântico", por sua vez, está relacionado com a ativação das áreas cerebrais responsáveis pela linguagem (áreas de Broca e Wernicke) e possibilitaria o surgimento da linguagem nos seus aspectos semântico, sintático e fonológico.

\section{Algumas conseqüências das teorias neurocientíficas para a psicanálise}

Considerando as contribuições de Damásio e Edelman, bem como as críticas feitas por Searle, gostaríamos de propor mais algumas aproximações entre neurociência e psicanálise, as quais, mesmo que apresentem um caráter especulativo e hipotético, podem servir para uma reflexão acerca das práticas terapêuticas atuais.

É somente com o surgimento de uma consciência elaborada (diretamente associada à linguagem) que podemos pensar num "inconsciente explícito", isto é, num inconsciente estruturado como uma linguagem (Lacan, 1964/1985). É o hipocampo que permite traduzir as memórias implícitas em memórias explícitas (LeDoux, 2000), possibilitando o recalque originário e dando origem ao "inconsciente explícito", ou seja, a um conjunto sistemático de memórias explícitas. Mas o que seria, então, recalcado no recalque originário? A resposta é simples: o que não é traduzido pelo hipocampo, isto é, aquelas memórias emocionais e procedurais que permanecem implícitas. Através do recalque originário, portanto, a consciência primária é suplantada pela consciência elaborada: doravante, toda a vivência subjetiva passa a ser mediada pela linguagem. Assim, a história do desenvolvimento de cada indivíduo é marcada por dois momentos: o pré-verbal e o verbal. O que não pode ser traduzido em palavras permanece, então, implicitamente, influenciando o comportamento emocional e os hábitos de cada indivíduo. Eventualmente, esse inconsciente implícito também poderia gerar sintomas. Podemos dizer que o inconsciente implícito é o núcleo do sistema inconsciente (Ics.) freudiano, território dos representantes pulsionais (Freud, 1915/2006). O inconsciente implícito é, portanto, psicossomático e pulsional.

Onde estaria então o que Freud chama de inconsciente reprimido (ou dinâmico)? Para responder a essa questão, é preciso considerar o sistema de memórias operacionais (ou de trabalho). Se considerarmos o ego como a instância recalcante, responsável tanto pela supressão 
[Unterdrückung] como pela repressão (ou recalque secundário) [Verdrängung], então poderemos dizer que o papel seletivo e executivo exercido pelo sistema de memórias de trabalho atua da mesma maneira que o"ego"freudiano. Logo, o inconsciente reprimido seria um efeito dessa atuação seletiva (supressão de memórias) do sistema operacional levada ao extremo numa experiência dolorosa (trauma) infantil. Portanto, a intensidade de uma experiência traumática é que determinará se uma memória explícita é apenas suprimida ou se é reprimida (i.e., radicalmente suprimida).

A época em que uma experiência dolorosa (traumática) ocorre também é fundamental para determinar o destino de uma memória recalcada. Nesse caso, se uma experiência traumática ocorrer no período pré-verbal (anterior à maturação do hipocampo), só haverá o registro de uma memória implícita relacionada ao evento traumático (Lyra, 2005). Isto determinará, posteriormente, a natureza do sintoma. Provavelmente, um trauma anterior à maturação do hipocampo - isto é, não traduzido como memória explícita - jamais poderá ser recordado num processo analítico. A técnica psicanalítica com pacientes que apresentem sintomas relacionados a traumas de uma infância primitiva deverá, assim, priorizar a síntese psíquica, isto é, o movimento de construção, de significação. As experiências inicialmente não-traduzidas deverão receber um significado por parte do sujeito em análise. Trata-se de um significado totalmente novo e original, tendo em vista que nada havia sido construído anteriormente.

Já os pacientes que apresentam sintomas relacionados a fases posteriores do desenvolvimento infantil (fases em que a verbalização [o simbólico] já está presente) tenderão, em tese, a responder melhor às técnicas analíticas, isto é, àquelas técnicas que estimulam o processo analítico do recordar e a re-significação das memórias explícitas. Nesses casos, costuma-se trabalhar com pacientes com um "ego" razoavelmente consistente, capaz de realizar plenamente seus mecanismos de defesa (em especial a repressão [recalque secundário]).

Logo, temos dois momentos cruciais no desenvolvimento infantil: o pré-verbal e o verbal. Ambos vão determinar eventuais sintomas no decorrer da vida adulta de um indivíduo. Quando a dinâmica do trauma envolve apenas memórias implícitas, os sintomas costumam ser de caráter psicossomático, ou aparecem como angústias extremas (como é o caso do pânico), e o tratamento deve estimular a construção, ou síntese psíquica. Por outro lado, se a dinâmica do trauma envolve memórias explícitas da infância, os sintomas costumam ter um caráter propriamente psíquico e a defesa aparece de maneira clara (exemplos: histeria, fobia e neurose-obsessiva), o que leva o terapeuta a conduzir o tratamento no sentido de uma desconstrução, ou análise psíquica (uma psicanálise, no sentido mais rigoroso!). 
O que tudo isso poderia nos ensinar a respeito do inconsciente? Primeiramente, fica clara a existência de dois "inconscientes": um implícito e outro explícito. Podemos, a partir da avaliação dos pacientes e de seus sintomas, chegar a uma afirmação razoável: o "inconsciente implícito" é psicossomático, enquanto o "inconsciente explícito" é propriamente psíquico. Em segundo lugar, podemos dizer que há uma evolução de uma vivência pulsional para o advento do desejo. Nesse caso, o desejo está ligado a um objeto explicitamente representado no contexto da linguagem. Em terceiro lugar, podemos questionar até que ponto uma psicanálise, no sentido mais rigoroso do termo (i.e., análise psíquica), poderia ajudar pacientes psicossomáticos ou com transtorno do pânico, tendo em vista que o processo de defesa do ego está mais comprometido nessas patologias. Em quarto lugar, podemos precisar o papel das diversas modalidades de recalque [tradução, repressão e supressão] na dinâmica das diferentes psicopatologias.

\section{Conclusão}

Eis, portanto, algumas questões a serem consideradas pela psicanálise no século XXI, e que demonstram a importância de um diálogo permanente com a neurociência.Trata-se, basicamente, das mesmas questões colocadas por Freud há pouco mais de cem anos; não obstante, a inserção de novos conceitos, advindos da neurociência, além de tornar mais clara a compreensão da metapsicologia freudiana, também se apresenta como um forte estímulo para a investigação psicanalítica. Esperamos que essa aproximação entre psicanálise e neurociência resulte num entendimento mais amplo do funcionamento da mente/cérebro, como também auxilie no tratamento das patologias de origem psíquica e/ou neurológica.

\section{The Unconscious and the Consciousness: From Psy- choanalysis to Neuroscience.}

Abstract: This paper consists of a revision concerning the concepts of "unconscious" and "consciousness", from the points of view of psychoanalysis and neuroscience. Thus, the author examines, initially, the Freudian Project; after that, he approaches Searle's critical view about psychoanalysis, and he presents, as well, Damásio's proposal and Edelman's conceptions about consciousness. Finally, the author indicates some possible contributions of the neuroscientific theories for psychoanalytic theory and clinic.

Keywords: Psychoanalysis. Neurosciences. Psychopatology. Psychotherapy. 


\section{L'Inconscient et la Conscience: de la psychoanalyse à la neurosciencie.}

Résumé: Cet article consiste d'une révision des concepts $d^{\prime}$ "inconscient" et de "conscience" d'après les points de vue de la psychoanalyse et de la neurosciencie. Dabord, on examine le Projet freudien; ensuite, I'approche critique de Searle sur la psychoanalyse, en présentant la proposition de Damasio et les conceptions d'Edelman sur la conscience. En conclusion, on indique quelques contributions possibles des théories neuroscientifiques à la clinique et aussi à la théorie psychoanalytique.

Mots-clés: Psychoanalyse. Neurosciencie. Psychopatologie. Psychothérapie.

\section{El Inconsciente y la Conciencia: del psicoa-nálisis a las ciencias neurológicas.}

Resumen: Este artículo consiste de una revisión sobre los conceptos de"inconsciente"y de la"conciencia",de los puntos de vista del psicoanálisis y de las ciencias neurológicas. El autor examina, al principio, el Proyecto freudiano; después, se acerca a la mirada crítica de Searle hacia el psicoanálisis, y presenta la propuesta de Damásio y las concepciones de Edelman sobre la conciencia. En conclusión, el autor indica algunas contribuciones posibles de las teorías de las ciencias neurológicas a la clínica y a la teoría psicoanalíticas.

Palabras-clave: Psicoanálisis. Ciencias Neurológicas. Psicopatología.Psicoterapia.

\section{Referências}

Damásio, A. R. (2000). O mistério da consciência. São Paulo: Companhia das Letras.

Edelman, G. M. (1998). Biologia da consciência. Lisboa: Instituto Piaget.

Freud, S. (1990). Além do princípio de prazer. In S. Freud, Edição standard brasileira das obras psicológicas completas de Sigmund Freud (Vol. 18, pp. 1185). Rio de Janeiro: Imago. (Trabalho original publicado em 1920)

Freud, S. (1990). O ego e o id. In S. Freud, Edição standard brasileira das obras psicológicas completas de Sigmund Freud (Vol.19, pp.11-83). Rio de Janeiro: Imago. (Trabalho original publicado em 1923)

Freud, S. (1990). Esboço de psicanálise. In S. Freud, Edição standard brasileira das obras psicológicas completas de Sigmund Freud (Vol. 23, pp. 165-237). Rio de Janeiro: Imago. (Trabalho original publicado em 1940)

Freud, S. (1990). Projeto para uma psicologia científica. In S. Freud, Edição standard brasileira das obras psicológicas completas de Sigmund Freud (Vol. 1, pp.385-529). Rio de Janeiro:Imago. (Trabalho original publicado em 1950) 
Freud, S. (2001). A interpretação de sonhos. Rio de Janeiro: Imago. (Trabalho original publicado em 1900)

Freud, S. (2006). O inconsciente. In S. Freud, Escritos sobre a psicologia do inconsciente (Vol. 2, pp. 13-74). Rio de Janeiro: Imago. (Trabalho original publicado em 1915)

Husserl, E. (2000). Os pensadores. São Paulo: Nova Cultural.

Izquierdo, I. (2002). Memória. Porto Alegre: Artmed.

Kandel,E.R.(1999).Biology and the future of psychoanalysis: A new intellectual framework for psychiatry. American Journal of Psychiatry 156, 505-24. (Publicado em 2003 na Revista de Psiquiatria do Rio Grande do Sul, 25(1), 139165)

Koyré, A. (1982). Estudos de história do pensamento científico. Rio de Janeiro: Forense Universitária.

Lacan, J. (1985) O seminário. Livro 11. Rio de Janeiro: Jorge Zahar (Trabalho original publicado em 1964)

LeDoux, J. (2000). Cérebro emocional: os misteriosos alicerces da vida emocional. Rio de Janeiro: Objetiva.

Lyra, C. E. S. (2005). Metapsicologia científica: revisando os fundamentos da teoria psicanalítica do recalque. Revista Neurociências Brasil, 2(2), 84-89.

Rosa, M. (1995). Introdução à psicologia. Petrópolis, RJ:Vozes.

Searle, J. R. (1997). A redescoberta da mente. São Paulo: Martins Fontes. 